\title{
The Influence of Textured Surfaces of Cosmetic Packaging on Consumers' Feelings
}

\author{
Siripuk Ritnamkam¹, Yada Chavalkul ${ }^{2}$ \\ ${ }^{1} \mathrm{PhD}$ Candidate in Multidisciplinary Design Research Program, \\ ${ }^{2}$ Assistant Professor in Industrial design, \\ Faculty of Architecture, \\ King Mongkut's Institute of Technology Ladkrabang, Chalongkrung Road, Ladkrabang, \\ Bangkok, 10520, Thailand \\ siripuk_pum@hotmail.com
}

\begin{abstract}
This study investigated what consumers' feelings were evoked when they touched different textured surfaces of 20 compact powder cases. Without seeing them, fifty respondents with and without an art-and-design-based background were asked to describe their feelings in their words as they touched the cases as well as explain them by provided words. The results show that different surface textures did evoke different respondents' feelings of which those familiar with the design were able to express a wider range. All participants were able to describe both the initial sense of physicality and complex feelings toward every textured surface investigated.
\end{abstract}

Keywords: sense of touch; textured surfaces; cosmetic packaging; consumers' feelings

eISSN 2398-4295 @ 2018. The Authors. Published for AMER ABRA cE-Bs by e-International Publishing House, Ltd., UK. This is an open-access article under the CC BY-NC-ND license (http://creativecommons.org/licenses/bync-nd/4.0/). Peer-review under responsibility of AMER (Association of Malaysian Environment-Behaviour Researchers), ABRA (Association of Behavioural Researchers on Asians) and cE-Bs (Centre for EnvironmentBehaviour Studies), Faculty of Architecture, Planning \& Surveying, Universiti Teknologi MARA, Malaysia.

DOI: http://dx.doi.org/10.21834/ajbes.v3i13.154 


\subsection{Introduction}

Human senses-vision, touch, taste, smell, and hearing-play a significant role in consumers' perceptions of a product. Consumers' perceptions are based on personal experiences, demographic characteristics, and cultures that affect their emotional responses. A positive response can lead to a decision to buy that product, whereas a negative response may result in avoidance of it (Crilly. 2004). Therefore, sensory perception strongly affects purchasing behavior.

Hanna and Wozniak (2000) stated that the process of sensory perception starts from consumers getting exposed intentionally or unintentionally to a stimulus in their immediate environment. Then, they direct their attention to it and sense it with their five sensory organseye, ear, Nose, mouth, and skin-that pass along input signals to their brain to get processed and interpreted.

Cosmetic packaging that addresses tactile sense is a new marketing scheme for attracting consumers and influencing their purchase decision. Packaging surface attributes such as sculpting, tapping, and velvet screen printing on the surface of the package are meant to convey a personality (McDougall .2010). Designers can use tactile sense to their advantage, especially for designing to attract consumers who are shopping for the product.

There have been several reported studies on conveying personalities in graphic design and packaging design. Pensasitorn (2013) conducted a study on the graphic design of packaging of convenience goods for seniors. The objective of the study was to find out the needs of senior consumers and their tastes in design elements of packaging such as color, illustration, and font. These elements were tested of which personalities they were able to convey. Another study on the graphic design of men's cosmetic packaging by Mitcharoenthavorn (2005) investigated the elements of graphic design such as color, illustration, and font that can convey various male personalities. A study by Chavalkul (2003) focused on using space to convey personalities; namely, the conveyance of different personalities are dictated by different arrangements of 4 main space elements: figure and ground, shape, composition of shape and frame, and structure. Focusing on color and shape elements of packaging design, Thiangthangtum (2013) investigated their uses to convey personalities perceived by consumers of functional drinks.

All of the studies cited in this subsection investigated how design elements convey the personality of a product from the point of view of visual perception, but no studies have been conducted yet from the point of view of tactile perception.

We were interested in this aspect of design and our research question was "what consumers' feelings do textured surfaces on compact cases of cosmetic powder evoke?"

\subsection{Literature Review}

The concept used in this study is a theory of sensory marketing. Sensory marketing covers product design, ambient store design, and marketing communication that targets the five senses: sight, sound, smell, taste, and touch. These integrated sensed features can evoke the hidden memories of consumers such that they may perceive a product as distinctive from other products in the market Toempornpukdiku, et al. (2013). 
Tactile senses of a packaging influence consumers' perception of the product. The feelings that consumers experience can influence their assessment of the product; therefore, sales clerks often encourage customers to touch the packaging of a product so that they may fall in love with or feel confident about the product and will be more likely to make a purchase (Marlow and Spence. 2011).

\section{Types of personalities}

From a review of relevant literature, the authors collected and grouped words are denoting different types of personalities for describing the perceptions of our target group. These words were mostly collected from the following four sources.

The first source is a work of Aaker (1997). Aaker created a brand personality scale based on established psychological theories, a personality scale used by marketers, and a qualitative research study on personality trait. His scale delineates personalities into 42 descriptive adjectives, grouped as five dimensions: sincerity, excitement, competence, sophistication, and ruggedness. Our study used 3 of the five dimensions that well suit a study on cosmetic packaging.

The second source is a work of Chavalkul (2003). This work was based on the idea of using elements of design to convey types of personalities.

The third and fourth sources are works of Choi (2006) and Chen (2009). They investigated the effects of textures of paper and plastic on consumers' feelings and their satisfaction toward the materials. Specifically, Choi's work involves a systematic approach to Kansei factors of tactile sense regarding surface roughness, while Chen's work involves tactile testing and characterization of packaging materials.

\subsection{Methodology}

\subsection{Pilot study}

This pilot study was conducted to find out the answer to this research question: "what consumers' feelings do textured surfaces in compact cases of cosmetic powder evoke?" The following are descriptions of the steps of the study, participants, packaging samples and questionnaires used.

\subsection{Steps of the study}

At first, we tried letting the respondents look at the packages while touching them, but it turned out that the words they used to describe their feelings were overwhelmingly influenced by the packages' visual appearances. Therefore, in the real test, the respondents were not allowed to see the packages-they were covered by a box-and the following steps were taken:

1. The two sample groups, who we fully expected to be able to give meaningful feeling words because of their quality described in Section 1.1 (Participants), were asked to touch without seeing the surfaces of 20 different product packages whose number and variety were large enough to be fair representatives of all of the available packages of this kind in the market, 
as described in Section 1.2 (Packaging samples);

2. They were asked, first, to describe their feelings in their own words toward the textured surface of each package in Part 1 of the questionnaire (shown in the Appendix) and then choose among 31 physicality and abstract feeling words we provided in Part 2 of the questionnaire; this exact order of reporting ensured that all of the feeling words collected would truly reflect both the feelings that the respondents were able to report in their own words and meaningful words that they might have not usually used in their daily lives but recognized when they were presented to them;

3. All of their responses were recorded and grouped, with respect to different personality words, to each textured surface were determined.

\subsection{Participants}

Two sample groups were studied: a group of 25 young females with an art-and-design-based background and another group of 25 young females with no such background. The first group was students in the Faculty of Architecture, King Mongkut's Institute of Technology Ladkrabang, Thailand, while the second group was students in the Faculty of Engineering, Science, Agriculture, and Education (Japanese major) of the same university. The reason for including only young females, at the ages of 18-22 years, was that they were more familiar with compact cosmetic powder products.

\subsection{Packaging samples}

There were three groups of 20 packaging samples of cosmetic powder investigated in this study, grouped according to different types of textures on the surface of the compact cases. These samples had either a high-relief texture pattern on their packaging surface made by molding or a very low-relief texture pattern made by printing after molding or a smooth surface made by molding.

All of these types of surfaces were produced by two kinds of technologies: molding and printing. Molding is done by using two types of molds-plain and sculpted. A plain mold is used for producing compact cases that have a smooth surface. A polished or plain waxed mold gives a glossy surface while a sand-blasted mold gives a dull surface, but a sculpted mold can produce a surface with a high-relief texture pattern. A surface of a compact case produced from any kinds of molds can be further decorated by printing. Silk-screen printing not only shows an illustration or text visually, but the printed illustration or text can be felt as a low-relief texture pattern when touched.

These 20 compact cases were selected because they had different surface textures and because their textures were on a horizontal surface such as the surfaces of the caps of jar and cases which were easier to sense by touch than those on a vertical surface such as the surfaces of bottles and tubes. The surface of the first type of compact cases was made by sculpted molds. Eight compact cases of this type were tested: compact cases No.1-8. They are shown in Fig. 1 and briefly described here:

No.1 had a small and short pattern on the surface with repeated subpatterns;

No.2 had straight edges and grids with repeated subpatterns;

No. 3 had curved edges and grids with repeated subpatterns; 
No.4 had repeated subpatterns;

No.5 had a medium relief surface with a symmetrical pattern;

No.6 had a high-relief surface and a small, long, and symmetrical surface pattern;

No.7 had a high-relief surface and a large free-shape pattern;

No.8 had curved edges with repeated subpatterns.

The surface of the compact cases of the second type was made by common molds and printing. Two cases of this type were tested: small cases No. 19-20.

The surface of the compact cases of the third type was made by plain molds. Ten cases of this type were tested: small cases No.9-15 that had a glossy surface and compact cases No.16-18 that had a dull surface.

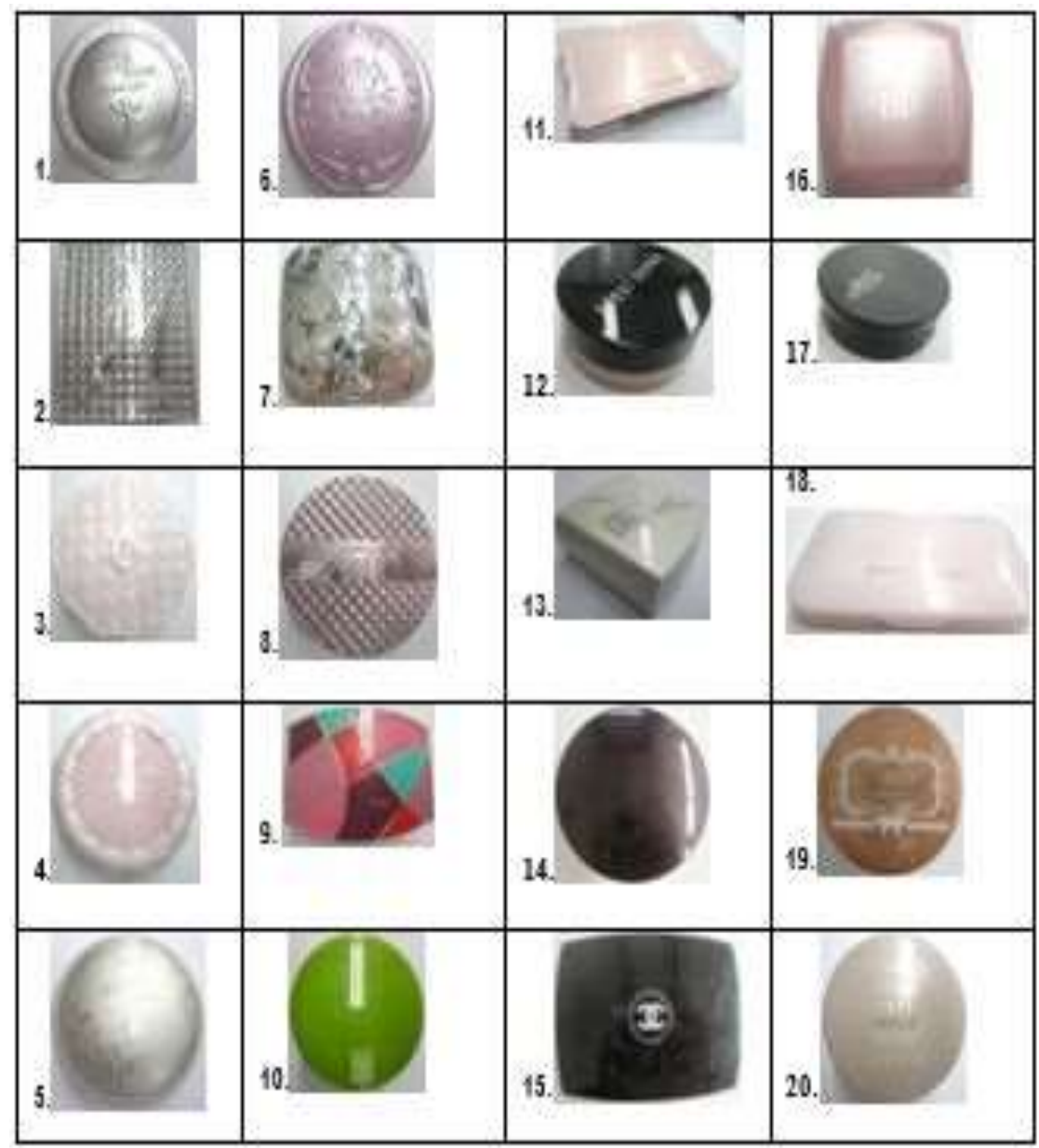

Fig. 1 Pictures of compact cases investigated in this study 


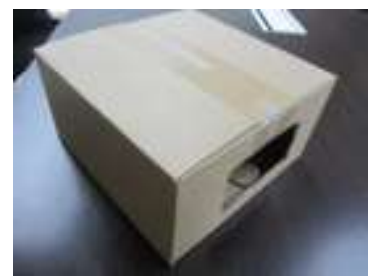

Fig. 2 The box where each test package was hidden in from sight
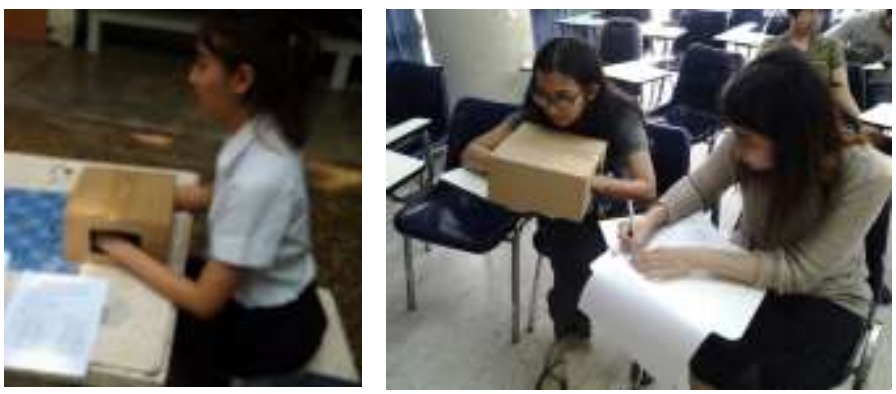

Fig. 3 The site where the survey was made

\subsection{Questionnaires}

Two questionnaires were used in this study: the first questionnaire collected the demographic information of the respondents and the second questionnaire evaluated the feelings of the respondents evoked by different surface textures. The second questionnaire consisted of 20 tables, each corresponding to one of the compact cases investigated. The tables were the same except for the heading which was the label of each small case. An example of these tables is shown in the appendix; it is the table for small case \#1. As can be seen, the tables consisted of 2 parts. Part I was for the respondents to describe their feelings in their words which were written down by one of the authors while the respondents were touching the compact cases, and Part II was for the respondents to tick some feeling words from a provided set to describe their feelings from which more than one word can be chosen. The provided set of feeling words consisted of the following: 9 adjectives from Chen's study (Chen.2009)_roughness, softness, slipperiness, sensual, sophisticated, playful, pleasurable, precious, and premium; 5 adjectives from Kyungmee Choi's study (Choi.2007)-solid, Glittery, smooth (physical), mature, and innovative; 12 adjectives from Aaker's study (Aaker.1997)—daring, exciting, spirited, cool, young, imaginative, unique, upto-date, charming, smooth (abstract), masculine, and rugged; and five adjectives from Yoda's study Chavalkul (2003)_formal, simple, delicate, glamorous, and feminine. The reason that we chose the 14 feeling words from Chen's and Choi's studies was that the objectives of their studies were similar to ours in that all of us wanted to find out the consumers' feelings toward surface textures, while the reason that we chose the 12 feeling words from Aaker's study was that these words were proven to be well-suited for describing cosmetic packaging, and the 
reason that we chose the 5 adjectives from Yada's study was that these words capture the feelings toward visual design elements that were not conveyed by those from the 3 studies above. All of these 31 feeling words comprised a spectrum of words from words that describe basic feelings of physicality to words that describe abstract feelings. These words are the following: roughness (physical), softness (abstract), slipperiness (physical), sensual (abstract), sophisticated (abstract), playful (abstract), pleasurable (abstract), precious (abstract), premium (abstract), solid (physical), glittery (physical), smooth (physical), mature (abstract), innovative (abstract), daring (abstract), exciting (abstract), spirited (abstract), cool (abstract), young (abstract), imaginative (abstract), unique (abstract), up-to-date (abstract), charming (abstract), smooth (abstract), masculine (abstract), rugged (physical), formal (abstract), simple (abstract), delicate (abstract), glamorous (abstract), feminine (abstract). They are most appropriate answers to our research question, "what consumers' feelings do textured surfaces in compact cases of cosmetic powder evoke?"

\subsection{Results \& Discussion}

This section reports the feeling words and specific textures that are the answers to our research question, "what consumers' feelings do textured surfaces in compact cases of cosmetic powder evoke?" The section is divided into two parts: Part I reports feeling words that the respondents expressed in their words and Part II report feeling words toward textured surfaces that the respondents picked out from the provided set.

4.1 The details of Part I of this section concerns the feeling words toward the textured surfaces that the respondents expressed in their words. It turned out that the respondents were able to describe their basic feelings of physicality and complex feelings toward the surfaces of every type freely. The words that they used are reported below.

For the first type of textures, the words that the respondents used to describe their basic feelings of physicality were relief, low relief, high relief, bumpy, and even, while the words that they used to describe their abstract feelings were gentle, cheerful, childlike, adolescent, cute, agile, seductive, strong, secure, busy, ultramodern, appealing, interesting, sentimental, working woman, uncomplicated, tender, natural, health-conscious, chic, tasteful, warm, beautiful, stylish, costly, slick, confident, cherished, informal, and repeating.

These words could be grouped further into 3 sets: the first set consisted of the following words that convey child-like characteristics-cheerful, childlike, adolescent, cute, uncomplicated, gentle, sentimental, cherished, tender, and informal; the second set consisted of the following words that convey adult-like characteristics-agile, ultramodern, working woman, tasteful, tasteful, confidence, seductive, appealing, interesting, strong, secure, repeating, busy, warm, stylish, chic, health-conscious and slick; and the third set consisted of the following words that cannot be grouped into the first two sets-natural and costly.

For the second type of textures, the word that the respondents used to describe their basic feelings of physicality were a low relief, while the words that they used to describe their abstract feelings were childlike, adolescent, interesting, strong, costly and sweet. These 
words could be grouped into two sets: the first set consisted of the following words that convey child-like characteristics-childlike, adolescent, strong, and sweet; and the second set consisted of the following words that cannot be grouped into the first set-interesting and costly.

For the third type of textures, the word that the respondents used to describe their basic feelings of physicality was even, while the words that they used to describe their abstract feelings were uncomplicated, costly, indifferent, slick, secure, strong, adolescent, childlike, interesting, working man, tender, stylish, warm, comfortable, priceless, easy-going, feeling good, meticulous, full bodied, agile, cute, luscious, flexible, and manly. These words could be grouped further into 3 sets: the first set consisted of the following words that convey male characteristics-uncomplicated, indifferent, secure, strong, working man, warm, comfortable, easy-going, feeling good, meticulous, full bodied, and manly; the second set consisted of the following words that convey female characteristics-slick, tender, priceless, agile, cute, luscious, stylish, and flexible; and the third set consisted of the following words that cannot be grouped into the first two sets-costly, adolescent, childlike, and interesting.

4.2 The details of Part II of this section concerns three types of textures that evoked different respondents' feelings that they expressed with words chosen from the provided set.

The first type of textures consisted of textures with high-relief patterns on the surfaces of Compact cases No.1-8. All of the textures were able to evoke basic feelings of physicality and complex feelings. Specifically, the feelings evoked by the surfaces of Compact cases No.2, No.6, and No.8 were described by all of the 31 words in the provided set; those evoked by the surface of Compact case No.1 were also described by all of the words in the set except formal; those of Compact case No.3 were described by all of the words in the set except structured and smooth; those of Compact case No.4 and No.5 were described by all of the words in the set except spirited, masculine, and rugged; and those of Compact case No.7 were described by all of the words in the set except rugged.

The second type of textures consisted of textures with very low-relief texture pattern on the surfaces of Compact cases No.19 -20. All of the textures were able to evoke basic feelings of physicality and complex feelings. The feelings evoked by the surface of Compact case No.19 were described by all the words in the set except cool and rugged; those of Compact case No.20 were described by all of the words in the set except innovative, daring, masculine, and rugged.

The third type of textures consisted of textures on a glossy surface of Compact cases No.9-15 and textures on a dull surface of Compact cases No.16-18. All of the textures were able to evoke underlying feelings of physicality and complex feelings. The feelings evoked by the surface of Compact case No.17 were described by all of the 31 words in the provided set; those evoked by the surface of Compact case No.9 were described by all of the words in the set except rugged; those of Compact case No.10 were described by all of the words in the set except sophisticated, masculine, and rugged; those of Compact case No.11 were described by all of the words in the set except roughness, innovative, and rugged; those of Compact case No.12 were described by all of the words in the set except playful and masculine; those of Compact case No.13 were described by all of the words in the set except 
innovative and imaginative; those of Compact case No.14 were described by all of the words in the set except playful, innovative, and rugged; those of Compact case No.15 were described by all of the word in the set except rugged; those of Compact case No.16 were described by all of the words in the set except rugged; and those of Compact case No.18 were outlined by all of the words in the set except sophisticated, playful, exciting, and rugged.

The results of this study agreed well with the theory of sensory marketing [ref] in that touch sense can actually evoke particular feelings toward a product. However, there were several feeling words obtained from this study that were quite different from those reported by Aaker (1997), Chavalkul (2003) , Choi (2006) and Chen (2009) probably because words that express feelings by young people in modern time, experiencing newer lifestyle, may be different from those popular in the times of the mentioned studies. For example; new expression that researcher has found out are agile, seductive, chic and easy-going. One limitation that can be improved in future study is the method to hide a package from the respondents' sight while they were feeling its surface texture. The hiding box that was used did not conceal the package in a foolproof manner: it was possible that some respondents could take a quick peek at the package inside if they intended to. A better hiding method should not allow this possibility. A fruitful and confirming subsequent future study would be to apply this study's methodology to products for men and male respondents. We can foresee a possibility that future consumers may be able to identify a product by touching the surface texture on its packaging alone.

There were several limitations to this study, namely: 1) the mood of each participant right before they were giving responses to the survey that strongly affected the feeling words that they reported could not be controlled; this factor is needed to control by adjusting the emotion of the respondents. Somehow relaxing is the choice. 2) the length of time of the survey might be too long for some respondents such that they might become too tired to keep their later responses consistent with their earlier ones or with the responses of the respondents who did not feel as tired; the respondents are offered to take a break while doing the response if they get tired and 3) there were textured packages in the market that were not included in this study and that might evoke new feeling and effect new feeling words.

\subsection{Conclusion}

From all of these results, conclusions can be made as follows: type 1 surface was the easiest for the respondents to describe their feelings toward because its protruded patterns were easily felt, while type 3 was the second easiest to feel because its patterns were coarse and smooth, but type 2 was the least easy to feel because the printed textures were only slightly protruding; furthermore, every respondent was able to report physicality feeling words toward all of the packages but only some of the non-design student respondents were able to report abstract feeling words while all of the design students were able to expressed their abstract feelings freely.

This study aimed to obtain words that express the respondents' feelings toward products of which the packagings were sensed solely by touch. The main results are as follows: tactile sensation of a textured surface could truly evoke different consumers' feelings; and both the words that describe basic feelings of physicality and the words that describe abstract feelings 
were successfully expressed by the respondents, but the respondents who had an art-anddesign-based background were able to express their feelings in a wider range of words than those who did not have it.

\section{Acknowledgements}

Arch.D. Program, in Multidisciplinary Design Research, Faculty of Architecture, King Mongkut's Institute of Technology Ladkrabang, Chalongkrung Road, Ladkrabang, Bangkok, Thailand.

\section{References}

Aaker, J, L. (1997). Dimensions of brand personality. Journal of Marketing Research. 34(3): 347-356.

Crilly, N, Moultrie, J and Clarkson, P, J. 2004. Seeing things: consumer response to the visual domain in product design. Design studies. 25(6): 557-560.

Chavalkul Y. (2003). elements of design. Bankok Thailand. Chulalongkorn University Publisher.

Chen, X. et. al. (2009). Materials' tactile testing and characterisation for consumer products' affective packaging design. Materials and Design. 30(9): 4299-4310.

Choi, $K$ \& Jun, C. (2007). A systematic approach to the Kansei factors of tactile sense regarding the surface roughness. Applied ErgoNomics. 38(7): 53-63.

Hanna, N. and Wozniak, R. (2001). consumer behavior an applied approach. Upper Saddle River: Prentice Hall.

McDougall, A. (2010). Alcan produce Multi-Sensory packaging for luxury Market. Retrived from http://www.cosmeticsdesign-europe.com/Packaging-Design/Alcan-produce-Multi-Sensory-packaging-for-luxurymarket. April2015.

McDougall, A. (2010). Multi-sensory packaging wins consumers' attention. Retrived from http://www.cosmeticsdesign-europe.com/Packaging-Design/Multi-sensory-packaging-wins-consumers-attention. April2015.

Marlow, N. (2011). To Touch or Not to touch; That is the question. Psychology \& Marketing. 28(3): 256-266.

Mitcharoenthavorn M. (2005). Graphic design on packages for men's cosmetics. A Thesis for the degree of Master of Fine and Applied Arts Program in Fine and Applied Arts Faculty of Fine and Applied Arts Chulalongkorn University Academic Year 2005. Bangkok Thailand.

Pensasitorn W. (2013). Graphic design on packaging for aging convenience goods. A Dissertation for the Degree of Doctor of Fine and Applied Arts Program in Fine and Applied Arts Faculty of Fine and Applied Arts Chulalongkorn University Academic Year 2013.Bankok Thailand.

Spence, C. (2011). Multisensory Design: Reaching out to Touch the consumer. Psychology \& Marketing.28(3): 267308.

Toempornpukdiku C, et al. (2013). Sensory Marketing . College of Management Mahidol University. 20 : 192. 
Thiangthangtum Y. (2013). The Study of Consumers Preference and Attitude on Packaging of Functional Drink in Bangkok and Boundary. Asia Color Association. 107-111

\section{Appendix}

Questionnaire for a pilot study entitled "The influence of textured surfaces of cosmetic packaging on consumers' feelings"

Research question: "what consumers' feelings do textured surfaces on compact cases of cosmetic powder evoke?"

Types of query: Part 1 consists of questions about demographic data while Part 2 consists of questions about feelings toward the textured surface

Instructions: Participants are asked to tick one or more boxes that describe their feelings toward a textured surface that they have touched without seeing it.

Part 1: Demographic data

Female; Age ... years; Faculty of ...; Major ...; Year in college ...; has an art-and-design-based background; has no art-and-design-based background

Part 2: Feelings toward the first to the $20^{\text {th }}$ specimen of textured surfaces

\begin{tabular}{|c|c|c|}
\hline \multicolumn{3}{|c|}{ The $1^{\text {st }}$ textured surface touched without being seen } \\
\hline Part I Describe your & Part II Choices & feeling words \\
\hline & 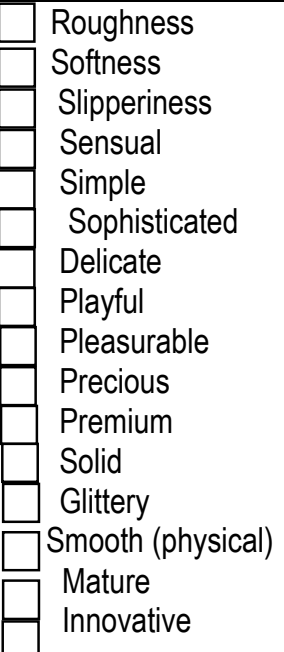 & \begin{tabular}{|c} 
Daring \\
Masculine \\
Exciting \\
Spirited \\
Cool \\
Young \\
Imaginative \\
Unique \\
Up-to-date \\
Glamorous \\
Rugged \\
Charming \\
Feminine \\
Smoot (abstract) \\
Formal
\end{tabular} \\
\hline
\end{tabular}

